Journal of Social Sciences 6 (1): 14-17, 2010

ISSN 1549-3652

(C) 2010 Science Publications

\title{
Nora: The Preservation of the Southern Thailand Performing Arts Development and Inheritance
}

\author{
Bubpachat Aupatummarakorn, Kla Somtrakul and Marisa Kaseyayothin \\ Research Institute of North Eastern Arts and Culture, Mahasarakham University, \\ Mahasarakham, 44000, Thailand
}

\begin{abstract}
Problem statement: Nora was the valuable Southern Thailand Performing Arts. The objectives of this study were to study: (1) historical background, identity, factor, tradition, belief and lifestyle of Southern Nora Team and (2) problem situations of Southern Thailand Performing Arts and guidelines in promoting occupation of the Southern Thailand Performing Arts. Approach: The research area in Southern Region included Patalung, Nokon-sitammarach and Songkla. The samples were selected by Purposive sampling including the expert group, practitioner group and general people, total of 110 persons. The instruments were the Structured Interview and Unstructured Interview, participatory observation form and non-participatory Observation form, focus group discussion and workshop. Data were classified into groups based on the studied issues. They were investigated by using triangulation technique and analyzed based on the research objectives. The research findings were presented by descriptive analysis. Results: (1) historical background and identity of Nora Team inherited from performing by the family and relatives for not less than 50 years. The team leaders loved and appreciated in Nora Performing Arts. So, they searched for knowledge from the experts and transferred knowledge for those who were interested in Nora Performing Arts. Every Nora Team was connected from the past until now. For the problem situations, found that they were caused by: (1) the decrease of audience's liking, (2) the import of new media caused Nora to be less popular, (3) the decrease of revenue and (4) for the inheritance, there was no one who would carry on. The pattern of developmental conservation and inheritance could be performed by organizing as the instructional curriculum of Nora Performance of every level of Southern Region. The searching information of Nora should be performed in the Website of the provincial culture. Kooks and CD should also be publicized. The Nora profession should be promoted in order to make income. The training and performance exhibition for publicizing through various kinds of media should be done for marketing in order to help the actor/actress to obtain revenue. For the development of Nora Performance Pattern, the development of management process in public relation, performance business, selling souvenir, as well as application of the story and performance to be concise, should be managed. Every performance should be evaluated for improving and developing the performance. Conclusion/Recommendations: Nora used to play its role in Southern society and culture. So, it was necessary to maintain and inherit further. This research could be used as a guideline in developing Nora Performance and planning for Southern Arts and Culture.
\end{abstract}

Key words: Nora, preservation, Southern Thailand, performing arts, development, imheritance

\section{INTRODUCTION}

Thai society in recent time has imported the Western Civilization. As a result, rapid growth of changes occurred, especially the technological progress. These kinds of advancement affected the national culture (Songkoon, 2006). For the performing arts in every region, they were influenced in wide area from Nora performance. Nora was a local performing art or local play of Southern people. It was always called or written in other names, for instance, Manohra, Manora, Manorah, Nohra and Norah. It was hypothesized that it was played according to the stories of the former incarnations of the Lord Buddha, Pra Suton-Manorah. Later on, when it was a long time ago, the other stories were added, for instance, the Southern folk tales, the content imitated from television drama and content of politics. Now, Nora was less popular since there were

Corresponding Author: Bubpachat Aupatummarakorn, Research Institute of North Eastern Arts and Culture, Mahasarakham University, Mahasarakham, 44000, Thailand 
changes of social values. According to these conditions, Nora Performance which was a local performing art with major cultural uniqueness and identity of Southern Region, with long historical background. Therefore, it should be preserved to be existed with the Southern Region further. Consequently, the research should be conducted in order to find the guidelines for sustainable preservation and development in the future.

Research objectives: The conducted research determined its objectives to study: (1) historical background, identity, component, custom, belief and living condition of Nora Troupe in Sothern Region, (2) the problem situations of Nora Performing Art in Southern Region in recent time and (3) the model of preservation, development and inheritance of Southern Performing Arts and model for enhancing the performance occupation of Nora in Southern Region.

\section{MATERIALS AND METHODS}

For this study, 3 provinces in Southern Region were selected including: Patalung, Nakon-sitammarach and Songkla. They were selected by Purposive Sampling. The informants consisted of 33 Key Informants, 48 Causal Informants and 30 General Informants. The instruments using for collecting data were: The Survey Form, Observational Form, Interview Form, Focus Group Discussion and Workshop. Data were collected by qualitative research methodology. Data from Field Study were collected and investigated by Triangulation Technique based on the objective. The findings were presented in descriptive analysis.

\section{RESULTS}

The findings of this research study were as follows:

- For historical background: Nora of each drama troupe was inherited its performance from family or relatives for not less than 50 years. Every drama troupe was similar from Nora Arena including $9 \mathrm{~m}$ length, $8 \mathrm{~m}$ width, $1 \mathrm{~m}$ height for the ancient Nora performing art and $20 \mathrm{~m}$ length, $7 \mathrm{~m}$ width and $1.5 \mathrm{~m}$ height. For modern Performing Art, recent Nora Arena would be the stage as Steel Nora Arena for the floor as the specified area. The curtain of Nora Performance was a single piece of curtain drawn as the view picture. The custom of performance started from the prologue, prelude and sacrificial ceremony for the teacher. It was believed that it could cause the performance to be smoothly successful
- For recent problem situations of Southern Nora performing arts, consisted of the audience's favor. In the former time, it was focused on dancing, poetry and witty for extemporaneous poetry. The Nora Performers still focused on the material as the former time. For the import of new media, when Thailand Economic and Society were changed especially various kinds of recreational media, the employment of Nora was decreased which wasn't relevant to the performers' living. For the inheritance of Nora Performing Arts, the ancient performances with knowledge and skill in Nora performing arts, were cherished. They scarcely transfer their knowledge to the others. Besides, the young age people weren't interested in carrying on since Nora dancing included the custom and tradition with complexity. Moreover, they weren't appreciated in their own local culture. Consequently, it needed to be preserved, enhanced and inherited (Fig. 1)

- According to the development of Southern Nora performing arts of Nora Drama Troupe for all of 3 aspects in recent time, there should be administration and management including the public relation for publicizing information, the specified wage of employment, development of story for performing by maintaining old content, content of recent society might be added, the costume should be appropriate with the performers' role. There should be 3 patterns of performance: (1) the traditional Nora Performing Arts as the ancient style, (2) the applied Nora performing Arts and (3) the Modern Nora Performing Arts blending the Western style such as tiffani show and cabaret show. The appropriateness should be considered as major thing

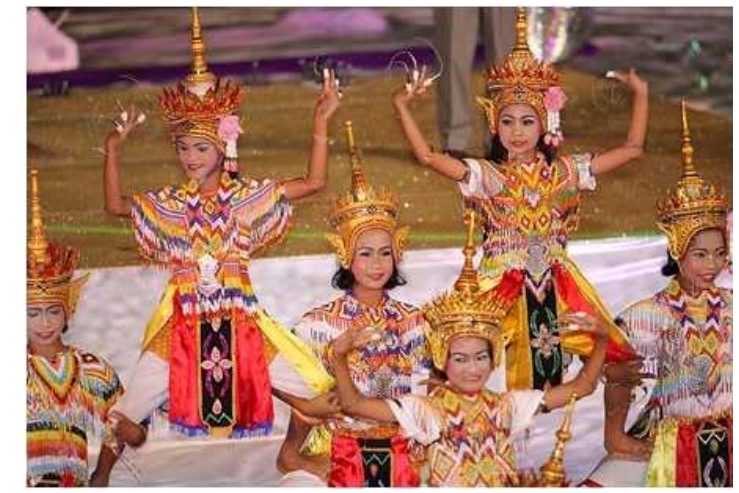

Fig. 1: Nora dancer folk art in the Southern part Thailand 


\section{J. Social Sci., $6(1): 14-17,2010$}

\section{DISCUSSION}

The research study could lead to discussion of findings as follows:

- The historical background and identity, Nora performing arts were related to Indian Culture especially Buddhism. The story outline of performance were the storied of the former incarnations of the Lord Buddha called "Pra Suton Manorah." It wasn't appeared when the Southern Region starting. But, it was developed until it included the clear custom and belief relating to society and culture of Southern people. It could be an identity of their locality which was adapted based on the appropriateness. It was supported by Ramitanon (2005) statement that the identity didn't occur independently based on the nature, it was occurred from cultural development during a period of time. Moreover, the culture was a social construction. Furthermore, the culture wasn't stopped or rigid. It included cycle patte4rn called "Circuit of Culture." So, those identities were produced, consumed and regulated in these cultures. The creation of meanings was developed through various systems of symbolic systems of representation regarding to different positions of many identities selected to use or develop as our identity by us

- For the issues of problem situations of Southern Nora performing arts in recent time, found that the favor of audiences was changed according to the age especially the import of globalization trend. There was a decrease of audiences and inheritors which had a direct effect on their revenue and existence of the drama troupe as the deterioration of culture. It was supported by Sutam (2003) statement that the deterioration of culture was a problem caused by 3 factors: (1) every field of knowledge based on Western Theories which was lacked of relation with local knowledge, (2) the technological and physical progresses accelerated the needs of country people until they left their own former knowledge and (3) the value of city society destroyed the old value of rural society

- For the issues of model for preservation of development and inheritance of Southern Nora performing arts and model in promoting the performance occupation of Southern Nora performing arts, Nora as the cultural media had to include the development of model for people with different values to be interested in it which was the development to be relevant to current situation.
Moreover, the bureaucratic sector had to have specified policy for related work offices. It was supported by Damsi (2001) suggestion that the model for preservation, development and inheritance of Nora performing Arts in every issue, had to be focused on major principle of performances, conserve, enhance the ancient model whereas develop the model for their survival. For local cultural development, the needs of key persons had to be considered. It was supported by Kaewtep (2001) statement the market building for audiences of local culture that: (1) it had to understand that "Who" were interested in the constructed work as well as developed the audiences' market simultaneously and (2) the development of audiences in quality was the development of the performance focusing on knowledge material blending with recreation expressing the value of culture of local performance. It would be sustainable further

\section{CONCLUSION}

The research titled Nora: The Preservation of the Southern performing arts development and inheritance, the research findings could be useful for society in promoting the Nora Performance to be worth for existing. Besides, the institution should use the content in constructing curriculum so that it could be taught in every level of Southern region by determining in learning substance of art, music, dancing, language and literature. Moreover, both of public and private sector should provide support. For future research, Nora would be experimented by blending with other fields of arts which was the development with the age or period.

\section{ACKNOWLEDGEMENT}

The research has been supported generously by the Mahasarakham University Research Fund. The authors would like to express their sincere appreciation for all of the support provided.

\section{REFERENCES}

Damsi, W., 2001. Rice Culture and Community Power around Songkla Lake. The Office of Research Support Fund (ORF), Bangkok, ISBN: 974-765459-8, pp: 180-183.

Songkoon, J., 2006. Cultural Qualitative Research. Prasankanpim, Kalasin, ISBN: 974195429 8, pp: 1. 
Kaewtep, G., 2001. Art of Educational Media and Culture. Adison Press Products, Bangkok, ISBN: 9741315899, pp: 64-87.

Ramitanon, C., 2005. Identity, culture and changing. http://www.soc.cmu.ac.th/ wsc/data/Identity28_3_ 05.pdf
Sutam, P., 2003. Dynamic of Community and Self Reliance in Western Region. Visionary Institution, Bangkok, ISBN: 974883386. 